\section{SHERLOCK HOLMES E A QUÍMICA: ANÁLISE E UTILIZAÇÃO DE FILMES DE FICÇÃO NO ENSINO DE QUÍMICA}

Sherlock Holmes and Chemistry: analysis and use of fiction films in chemistry teachin

Sherlock Holmes y la química: análisis y utlilización de películas de ficción destinados a la enseñanza de quimica

\section{Resumo}

Os filmes de curta e longa-metragem são apontados como recursos importantes para o ensino de ciências. São consideradas obras de ficção científica os objetos de entretenimento que lidam principalmente com o impacto da ciência, tanto verdadeira como imaginária, sobre a sociedade ou indivíduos. Esse trabalho teve como objetivo analisar cenas do filme Sherlock Holmes a partir do plano conceitual-fenomenológico a fim de se executar uma oficina com base neste filme para alunos do Ensino Médio de Química. A análise mostrou 13 objetos ficcionais com elementos linguísticos. Com base nisso, foram selecionadas seis cenas do filme para uma discussão na oficina, de forma a avaliar a percepção da Química no filme por parte dos alunos. Foi observado que, no início, os alunos tiveram dificuldades em perceber elementos de Química nas cenas, fazendo com que eles apontassem apenas conceitos básicos. No decorrer da oficina foi notado que alguns alunos começaram a perceber mais a Química nas cenas, chegando a extrapolar o enredo do filme e relacionar os conteúdos com outras situações e contextos.

Palavras-Chave: ensino de química; filmes; ficção cientifica.

\section{Abstract}

Short films and feature-length are singled out as important resources for science teaching. Objects of entertainment that deal mainly with the impact of science, both true and imaginary, on society or individuals are considered works of science fiction. This work aimed to analyze scenes of the Sherlock Holmes film from the conceptual-phenomenological plan to, from this, to execute a didactic workshop based on this film for students of the High School of Chemistry. The analysis showed 13 fictional objects with linguistic elements. Based on this, six scenes were selected from the film for a discussion in the workshop, in order to assess the students' perception of Chemistry in the film. It was observed that in the beginning, students had difficulties in perceiving elements of Chemistry in the scenes, causing them to point out only basic concepts. During the workshop it was noticed that some students began to perceive more chemistry in the scenes, getting to extrapolate the plot of the film and relating the contents with other situations and contexts.

Keywords: Chemistry teaching; movies; scientific fiction.

\section{Resumen}

Los Cortometrajes y largometraje se exponen como importantes recursos para la enseñanza de la ciencia. Se consideran obras de la ciencia ficción. Los objetos de entretenimiento que tienen que ver principalmente con el impacto de la ciencia, tanto reales como imaginarios. Este estudio tuvo como objetivo analizar la película Sherlock Holmes escenas del plan conceptual-fenomenológica, a partir de esto, implementar un taller basado en esta película a la Escuela Media de estudiantes de la química. El análisis mostró 13 objetos ficticios con elementos lingüísticos. Con base en esto, han sido seleccionados seis escenas de la película para una discusión en el taller con el fin de evaluar la percepción de la química en la película por los estudiantes. Se observó que al principio, los estudiantes tenían dificultad para entender los elementos químicos en las escenas. Durante el taller se ha observado que alguns estudiantes empezó a darse cuenta que hay más química en las escenas, llegando hasta sobrepasar la trama de la película y relacionar contenido con otras situaciones y contextos.

Palabras clave: enseñanza de la quimica; película; ciencia ficcíon.
AUTORES:

GUSTAVO SILVA DE

AMORIM ${ }^{1}$

ORCID 0000-0003-4424-8465

${ }^{1}$ Universidade Federal

Rural de Pernambuco

(UFRPE)

JOÃO ROBERTO RATIS TENÓRIO DA SILVA ${ }^{2}$

ORCID 0000-0001-9682-8889

Universidade Federal

Rural de Pernambuco

(UFRPE)

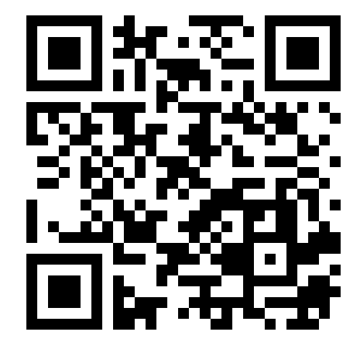

Para citar este artigo:

AMORIM, G. S.; SILVA, J. R. R. T. Sherlock Holmes e a Química: Análise e Utilização de filmes de ficção no Ensino de Química. Revista Eletrônica Ludus Scientiae, Foz do Iguaçu, v. 01, n. 01, p. 47-57, jan./jul. 2017. 


\section{INTRODUÇÃO}

As obras cinematográficas são apontadas por diversos autores como importantes recursos para o ensino. Autores como Gomes-Maluf (2001), Gomes-Maluf e Souza (2008) e Piassi e Pietrocola (2009) apresentam trabalhos voltados para essa temática. A partir de tais pesquisas, nota-se que, frequentemente, professores estão usando diferentes tipos de filmes como ferramentas didáticas no ensino de ciências. Segundo Piassi e Pietrocola (2009) as possibilidades e implicações dessa prática podem ser situadas em diversos âmbitos, não apenas no ensino de conceitos, mas também na abordagem de aspectos normalmente não desenvolvidos em sala de aula, como questões que versam sobre a natureza do conhecimento científico e as relações da ciência com a tecnologia e sociedade.

Na literatura, observam-se trabalhos que discutem como alguns filmes comerciais podem ser usados em estratégias em sala de aula, partindo do caráter lúdico desse tipo de material, proporcionando a diversão e o prazer. Quintino e Ribeiro (2010), por exemplo, apresentam uma estratégia utilizando os filmes Um Dia Depois de Amanhã, O Núcleo: missão ao centro da Terra e $O$ Óleo de Lorenzo. Os autores ofereceram um minicurso, com carga horária de $24 \mathrm{~h}$, para tentar promover uma aprendizagem significativa nos alunos com o uso desses filmes. Quintino e Ribeiro (2010) afirmam que a estratégia foi útil na motivação dos alunos, mesmo frente à dificuldade deles em perceber a relação de alguns conceitos químicos com os filmes.

Por sua vez, Santos e Aquino (2011) usaram o filme "Perfume: a história de um assassino" para a abordagem de conteúdos de Química Orgânica e Bioquímica com alunos do $3^{\circ}$ ano do Ensino Médio. Além do relato de experiência, as autoras discutem sobre a dificuldade e resistência que alguns professores apresentam em usar filmes como recurso para o ensino de Química. Muitos justificam a não utilização por gosto pessoal. Já outros afirmam que não receberam formação para tal. Segundo as autoras, a justificativa mais recorrente para não utilização é a incapacidade de fazer relações entre os filmes disponíveis e o conteúdo científico requerido pelo currículo.

Com relação a essa última dificuldade colocada por Santos e Aquino (2011), sugere-se uma análise prévia do filme para o estabelecimento de relações sobre cenas dos filmes e conteúdos científicos específicos. Diante disso, Piassi e Pietrocola (2006) propõem um instrumento de análise a partir de categorias que fazem parte do chamado plano conceitual-fenomenológico. Segundo os autores, com tal análise é possível escolher quais objetos ficcionais contidos nos filmes podem ser usados em sala de aula. Segundo o plano conceitual-fenomenológico, cada objeto ficcional pode ser classificado em: linguístico, objetivo e fenomenológico. Essa divisão pode deixar claro para os professores que conteúdo de científico pode ser explorado, a partir do "gatilho" existente no recorte escolhido, podendo ser uma fala ou discussão (elemento linguístico), uma ação ou execução de uma tarefa (elemento objetivo) ou um objeto ou fenômeno existente na cena (elemento fenomenológico). Assim, a abordagem em sala de aula pode ser motivada a partir de questões, tais como:

- Por que a personagem argumentou tal ponto? (linguístico);

- Com base no conhecimento científico, o que o grupo quis fazer com essa máquina na cena? (objetivo);

- Como essa explosão foi causada, com base no que estudamos na disciplina? (fenomenológico).

Dessa forma, advoga-se que uma análise prévia no filme pode ser útil para indicar caminhos de como os professores podem usar cenas e relaciona-las com os conteúdos específicos.

Diante desse contexto, o objetivo deste artigo é apresentar uma análise dos objetos ficcionais presentes em um filme de ficção (Sherlock Holmes) a partir do plano conceitual-fenomenológico (PIASSI e PIETROCOLA, 2006) e analisar como alunos do ensino médio percebiam a química presente 
no filme a partir de uma oficina didática elaborada com base na análise dos objetos ficcionais analisados presentes na obra.

\section{FUNDAMENTAÇÃO TEÓRICA}

\section{O lúdico na sala de aula de Química - Filmes de ficção científica em sala de aula}

O uso de atividades lúdicas no ensino de Química vem sido discutido por diversos autores, sobretudo a partir do início da década de 2000, como apontam os levantamentos realizados por Crespo e Giacomini (2011) e Soares (2016). Esses trabalhos apontam para um aumento significativo de publicações que versam sobre o uso de jogos, teatros, história em quadrinhos, filmes e seriados no ensino de conceitos químicos.

O uso de filmes de ficção como atividade lúdica no ensino de conceitos químicos pode apresentar um enorme potencial, por se apresentar como um tipo de mídia amplamente consumido pelo grande público, sendo um dos principais meios de entretenimento. Assim, o uso de filmes ou seriados, principalmente aqueles que já são conhecidos pelos alunos, pode motivar e ser o ponto de partida para a discussão de vários conteúdos.

O uso de vídeos como atividade lúdica em sala de aula se iniciou com as propostas do Instituto Nacional do Cinema Brasileiro (INCE), no ano de 1936 (CARVALHAL, 2009). Segundo Melo (2013), existem registros do ano de 1947 que relatam que o INCE atendia cerca de 800 escolas por ano, realizando mais de 2000 projeções anuais, já mostrando o potencial desse recurso em sala de aula. Levar o cinema para o ambiente escolar nas décadas de 1930 e 1940 foi um recurso sofisticado demais para fazer parte de uma reforma educacional que tinha como maior necessidade uma reforma estrutural e que os alunos frequentassem periodicamente (FRANCO, 1987).

No que diz respeito, especificamente, ao uso de filmes de ficção científica ou aventura como atividade lúdica, desde a década de 1970 há o registro de propostas de ensino, como a encontrada no trabalho de Allen (1976). Estima-se que, na época, mais de quinhentos tipos de obra de ficção poderiam ser usados por professores em sala de aula (ALLEN, 1976). É importante frisar que a década de 1970 é repleta de diversos filmes de ficção científica com grande potencialidade de uso em sala de aula, tais como a série Star Trek (década de 6o), Star Wars: episode IV (1977), Contatos Imediatos de Terceiro Grau (1977), A Conquista dos Planetas dos Macacos (1972), etc.

Filmes classificados como sendo de ficção científica geralmente extrapolam conceitos e fatos científicos reais, permitindo criar ambientes imaginários em que o conhecimento científico se torna um "pano de fundo". O termo ficção sempre trás diferentes definições, as quais carregam o mesmo significado. Segundo o dicionário Aurélio", o termo ficção significa "ato ou efeito de fingir. Invenção fabulosa ou engenhosa. Criação de caráter artístico, baseada na imaginação, mesmo se idealizada a partir de dados reais". São consideradas obras de ficção científica os objetos de entretenimento que lidam principalmente com o impacto da ciência, tanto verdadeira como imaginária, sobre a sociedade ou indivíduos. Tais obras carregam em seus elementos uma base científica, mesmo que algumas vezes essa base seja considerada fantasiosa, especulativa ou até mesmo não confiável. A classificação de filmes em ficção científica é dada previamente pelas agências de entretenimento COCIND (Coordenação de Classificação Indicativa) e DEJUS (Departamento de Justiça, Classificação, Títulos e Qualidade).

Piassi e Pietrocola (2006) apresentam possibilidades de uso de filmes de filmes de ficção científica como recurso didático em sala de aula. Para isso, os autores propõem um instrumento de 
análise denominado plano conceitual-fenomenológico, o qual é composto por três tipos de modalidades de elementos:

- Elementos linguísticos: o uso da linguagem, ou seja, a terminologia empregada;

- Elementos objetivos: artefatos e seres, tais como máquinas, animais, plantas ou mesmo objetos de origem natural;

- Elementos fenomenológicos: os fenômenos apresentados na história, tais como efeitos, explosões, luzes e sons.

Segundo Piassi e Pietrocola (2006), nesses três corpos de elementos é possível situar a forma pela qual a Ciência é apresentada em obras de ficção, de forma a se aproveitar tais elementos no trabalho em sala de aula. Os autores ressaltam a importância da identificação desses elementos antes do uso dos filmes em estratégias de ensino, de forma a se estabelecer o que se chama de "suspensão de incredibilidade", que se refere à constituição de uma "fé poética". São elementos narrativos que permitem o autor/diretor da obra convencer o espectador que a história é dotada de fatos verdadeiros, permitindo um mergulho da pessoa no enredo.

Ao se usar filmes de ficção científica em sala de aula, é necessária, também, uma discussão acerca do fundamento de uso de vídeos em aulas de Ciências. Para isso, neste trabalho, optou-se pela utilização da discussão teórica apresentada por Moran (1995) e Ferrés (1996).

\section{Uso de vídeos em sala de aula}

Ferrés (1996) aponta que o vídeo, em sala de aula, não pode substituir o professor, sendo essencial a mediação docente para discussão dos conteúdos presentes de forma explícita ou implícita no recurso. Além disso, a eficácia do uso do vídeo depende, também, da estratégia na qual ele está inserido, sendo importante um planejamento adequado da intervenção (FERRÉS, 1996).

No que diz respeito quanto ao tipo de uso, Moran (1995) coloca que o vídeo pode ser utilizado de acordo com as classificações apresentadas no Quadro 1 abaixo:

Quadro 1: Classificação do tipo de uso de vídeo em sala de aula (MORAN, 1995).

\begin{tabular}{|c|c|}
\hline TIPO DE USO DO VÍDEO EM SALA DE AULA & FUNÇÃO \\
\hline Sensibilização & $\begin{array}{c}\text { Introduzir um novo assunto, motivando os alunos para } \\
\text { se engajar no início de algum conteúdo. }\end{array}$ \\
\hline Ilustração & $\begin{array}{c}\text { Demonstrar cenários ou fenômenos que não são } \\
\text { possíveis ver no mundo real. }\end{array}$ \\
\hline Simulação & $\begin{array}{c}\text { É uma forma de vídeo ilustração mais sofisticada, em } \\
\text { que há a simulação de fenômenos e processos. }\end{array}$ \\
\hline Como conteúdo de ensino & Aborda direta ou indiretamente o conteúdo. \\
\hline Vídeo produção & $\begin{array}{c}\text { Os alunos ou o professor produzindo o próprio vídeo, } \\
\text { executando todas as etapas, incluindo pré e pós- } \\
\text { produção. }\end{array}$ \\
\hline
\end{tabular}

Seguindo essa mesma linha, Ferrés (1996) também apresenta uma categorização quanto ao uso:

- Vídeo-lição - exibido como uma "aula expositiva” do conteúdo; 
- Vídeo-apoio - função de ilustrar o discurso do professor;

- Vídeo-motivador - ferramenta de motivação para o aluno;

- Vídeo-processo - o aluno sendo responsável pela produção do próprio vídeo;

- Vídeo monoconceitual - vídeos curtos que abordam apenas um conceito de forma direta;

- Vídeo interativo - vídeo associado a outro tipo de mídia, como softwares ou hipermídias.

Assim, para a escolha do filme de ficção a ser usado em sala de aula, além de uma análise no plano conceitual-fenomenológico (PIASSI; PIETROCOLA, 2006), sugere-se a escolha do tipo de uso, segundo as classificações de Moran (1995) e Ferrés (1996).

\section{METODOLOGIA}

A metodologia de execução deste trabalho se dividiu em três etapas: 1) escolha do filme de ficção científica a ser usado; 2) análise dos elementos ficcionais do filme, segundo o plano conceitualfenomenológico; 3) Elaboração e execução da oficina e; 4) Análise da percepção dos alunos acerca dos conteúdos químicos presentes em algumas cenas do filme.

De acordo com a primeira etapa, o filme Sherlock Holmes (2009) foi escolhido neste trabalho por possuir, em algumas cenas, elementos ficcionais com potencialidade de discussão de conteúdos químicos e por se enquadrar na categoria ficção científica, que permite sua classificação como de ficção científica. Segundo o COCIND², a obra é classificada, também, como suspense, comédia, aventura e ação.

O enredo do filme Sherlock Holmes é baseado nas obras do autor britânico Arthur Conan Doyle sobre um detetive chamado Sherlock Holmes. O autor explora uma série de aventuras, colocando o detetive em missões, explorando como ele desvenda casos, usando a lógica dedutiva e o método científico, com seu parceiro Dr. John Watson. O filme, especificamente lançado em 2009 (em 2010 no Brasil), se passa na Inglaterra do século XIX. Em seu enredo, conta a história de uma série de assassinatos que acontece na cidade de Londres. Assim, o detetive Sherlock Holmes, interpretado por Robert Downey Jr., e seu parceiro, o Dr. Watson, vivido por Jude Law, devem encontrar o assassino.

No que diz respeito à segunda etapa, a análise dos objetos ficcionais se deu a partir do uso do plano conceitual-fenomenológico (PIASSI e PIETROCOLA, 2006), elencando-os e dividindo nos elementos linguísticos, objetivos e fenomenológicos, segundo a discussão apresentada neste artigo. Após a identificação de tais elementos presentes no filme Sherlock Holmes, verificou-se aqueles que aparecem com maior frequência, de forma a direcionar a elaboração e aplicação da oficina, além da seleção dos conteúdos químicos que seriam trabalhados.

Na terceira etapa, a oficina foi planejada a partir da ideia de utilizar filmes que tivessem em suas cenas alguma referência a conceitos químicos. A oficina, que foi batizada "Cinequímica: A química por trás do filme Sherlock Holmes”, teve uma carga horária de 12h, dividida em três dias de aplicação. Participaram da oficina 32 alunos do $2^{-}$e $3^{\circ}$ anos do Ensino Médio, os quais trabalharam em grupos, totalizando 4 grupos de 8 alunos cada.

Para indicação dos conteúdos, foi usada a análise dos objetos ficcionais, referente à segunda etapa. Após essa análise, foram selecionadas seis cenas, para que elas fossem usadas durante as intervenções, após a exibição completa do filme. No que diz respeito à classificação segundo o tipo de uso de vídeos, no planejamento da oficina optou-se pelo vídeo-motivador (FERRÉS, 1996) e vídeo

${ }^{2}$ COCIND (Coordenação de Classificação Indicativa) - <http://www.justica.gov.br/seus-direitos/classificacao> Acessado em: 24 de maio de 2017. 
sensibilização (MORAN, 1995). As cenas selecionadas abordavam os seguintes conteúdos/temas: propriedades organolépticas das substâncias, transformações químicas e físicas, propriedades das substâncias, elementos e substâncias e substâncias inflamáveis.

Como os participantes da oficina foram alunos do $2^{-}$e $3^{\underline{0}}$ anos do ensino médio, eles já tinham estudado os conteúdos trabalhados com o filme. Então, o objetivo da intervenção foi verificar a percepção deles dos conceitos químicos para posterior discussão, analisando como essa percepção aumentava ao longo das atividades. As atividades da oficina, por dia, foram:

- Primeiro dia: exibição do filme, formação dos grupos e produção textual - realizada individualmente - sobre quais os possíveis conceitos químicos que poderiam ser estudados a partir do filme);

- Segundo dia: aula expositiva dialogada, com base na produção textual realizada pelos alunos no primeiro dia, abordando os conceitos químicos que apareciam no filme, com o uso de algumas cenas selecionadas;

- Terceiro dia: apresentação de seminários, em que os alunos explicaram as seis cenas selecionadas, usando o conhecimento químico discutido no encontro anterior. Além disso, foi solicitado mais uma produção textual, a qual foi feita individualmente.

\section{RESULTADOS E DISCUSSÃO}

\section{Análise do plano conceitual-fenomenológico para seleção dos conteúdos e cenas do filme para a oficina}

No filme Sherlock Holmes, analisou-se o máximo de objetos ficcionais presentes na obra. No Quadro 2 encontram-se os objetos ficcionais com a classificação dos elementos de acordo com a proposta conceitual-fenomenológica e associado ao conceito científico proposto.

Quadro 2: Classificação dos objetos ficcionais contidas no filme Sherlock Holmes.

\begin{tabular}{|c|c|c|c|}
\hline $\begin{array}{l}\text { TEMPO DE FILME } \\
\text { (MINUTOS) }\end{array}$ & OBJETO FICCIONAL & $\begin{array}{l}\text { PLANO CONCEITUAL- } \\
\text { FENOMENOLÓGICO }\end{array}$ & CONTEÚDO PROPOSTO \\
\hline $03: 52$ & Lâmina de cristal & Elemento objetivo & Cristalização \\
\hline $07: 05$ & "Sinto o cheiro de pólvora" & Elemento linguístico & Propriedades organolépticas \\
\hline $43: 50$ & $\begin{array}{l}\text { "ele usava o mesmo } \\
\text { perfume parisiense" }\end{array}$ & Elemento linguístico & Propriedades organolépticas \\
\hline 44:00 & Laboratório improvisado & Elemento objetivo & $\begin{array}{l}\text { EPI - Equipamento de } \\
\text { proteção individual }\end{array}$ \\
\hline $44: 05$ & $\begin{array}{l}\text { "Putrefação! Sulfato de } \\
\text { Amônia, entre outros } \\
\text { aromas. Fósforo! } \\
\text { Formaldeídos" }\end{array}$ & Elementos linguísticos & Propriedades organolépticas \\
\hline $44: 25$ & $\begin{array}{l}\text { Homem usando um conta- } \\
\text { gotas e preparando um } \\
\text { composto no qual } \\
\text { aparecem faíscas e fumaça }\end{array}$ & $\begin{array}{l}\text { Elemento } \\
\text { fenomenológico }\end{array}$ & Preparação de substâncias \\
\hline $44: 40$ & Formula escrita no papel & Elemento objetivo & Reações químicas \\
\hline $44: 45$ & $\begin{array}{l}\text { "Potássio, magnésio e } \\
\text { ácido sulfídrico" }\end{array}$ & Elemento linguístico & Elementos e substâncias \\
\hline $45: 00$ & $\begin{array}{l}\text { "Vai tirar todo o ferro da } \\
\text { tinta desde que o papel } \\
\text { não esteja queimado } \\
\text { demais" }\end{array}$ & Elemento linguístico & Elementos e substâncias \\
\hline $45: 15$ & Mistura de reagentes & Elemento objetivo & Preparação de substâncias \\
\hline
\end{tabular}




\begin{tabular}{|c|c|c|c|}
\hline 1:06:00 & $\begin{array}{l}\text { Um desmaio depois de } \\
\text { beber vinho com um } \\
\text { sedativo }\end{array}$ & Elemento objetivo & Fármacos \\
\hline 1:15:15 & $\begin{array}{l}\text { A queima de uma amostra } \\
\text { de cabelo liberou uma } \\
\text { chama de cor amarela }\end{array}$ & $\begin{array}{l}\text { Elemento } \\
\text { fenomenológico }\end{array}$ & Propriedades dos metais \\
\hline 1:16:00 & $\begin{array}{l}\text { Chama amarela, com veios } \\
\text { verdes }\end{array}$ & Elemento linguístico & Propriedades dos metais \\
\hline 1:18:02 & Laboratório improvisado. & Elemento objetivo & $\begin{array}{l}\text { EPI - Equipamento de } \\
\text { proteção individual }\end{array}$ \\
\hline 1:19:00 & Gás e chamas & $\begin{array}{l}\text { Elemento } \\
\text { fenomenológico }\end{array}$ & Combustão \\
\hline 1:22:00 & Explosões & $\begin{array}{l}\text { Elemento } \\
\text { fenomenológico }\end{array}$ & Combustão \\
\hline 1:38:00 & $\begin{array}{l}\text { "Um leve aroma de } \\
\text { amêndoas, sinais de ácido } \\
\text { cianídrico" }\end{array}$ & Elemento linguístico & $\begin{array}{l}\text { Substâncias tóxicas e } \\
\text { propriedades organolépticas }\end{array}$ \\
\hline 1:40:20 & $\begin{array}{l}\text { "Converte o líquido em } \\
\text { gás" }\end{array}$ & Elemento linguístico & Transformação física \\
\hline $1: 48: 45$ & $\begin{array}{l}\text { "Uma cola leve, receita } \\
\text { antiga. Uma mistura de } \\
\text { ovo e mel, criada para se } \\
\text { dissolver em água" }\end{array}$ & Elemento linguístico & Preparação de materiais \\
\hline 1:49:00 & $\begin{array}{l}\text { "uma substância } \\
\text { paralisante ativada com a } \\
\text { combinação de cobre e } \\
\text { água" }\end{array}$ & Elemento linguístico & Reações químicas \\
\hline $1: 49: 40$ & $\begin{array}{l}\text { "Você usou o mesmo } \\
\text { composto para explodir o } \\
\text { cais. Um líquido } \\
\text { inflamável, insípido e } \\
\text { inodoro, mas que queima } \\
\text { com uma coloração rosa } \\
\text { característica” }\end{array}$ & Elemento linguístico & Reação de combustão \\
\hline 1:50:10 & $\begin{array}{l}\text {-“Uma arma Química, } \\
\text { destilada do cianeto" }\end{array}$ & Elemento linguístico & $\begin{array}{l}\text { Separação de misturas } \\
\text { (Destilação) }\end{array}$ \\
\hline 1:50:30 & $\begin{array}{l}\text {-"Há! Uma toxina refinada } \\
\text { a partir de uma planta" }\end{array}$ & Elemento linguístico & $\begin{array}{l}\text { Separação de misturas } \\
\text { (Extração) }\end{array}$ \\
\hline
\end{tabular}

Foram identificados 23 objetos ficcionais, os quais estão apresentados no Quadro 02. Desse total, 13 objetos apresentaram elementos linguísticos com potencialidade para discussão em sala de aula sobre conteúdos químicos. Os conteúdos compreendidos nesses 13 objetos ficcionais com elementos linguísticos foram: separação de misturas, reação de combustão, reações químicas, preparação de materiais, substâncias tóxicas e propriedades organolépticas, propriedades dos metais e elementos e substâncias. Dessa forma, os conteúdos químicos selecionados para a oficina foram: propriedades organolépticas, transformações químicas e físicas, propriedades das substâncias, elementos e substâncias. As seis cenas selecionadas para a discussão durante a oficina versavam sobre esses conteúdos, sendo expressos a partir de elementos linguísticos.

\section{Percepção dos alunos da Química presente no filme Sherlock Holmes}


No Quadro 3 encontra-se a análise da primeira atividade (produção textual após a exibição do filme). O objetivo desta atividade foi observar se os alunos conseguiam fazer alguma relação do filme com conceitos químicos, de acordo com os objetos ficcionais analisados previamente.

Quadro 3: Análise da atividade o1 - produção do texto para percepção da Química.

\begin{tabular}{|c|c|c|}
\hline \multicolumn{3}{|c|}{ ATIVIDADE o1 - PRODUÇÃO TEXTUAL APÓS EXIBIÇÃO DO FILME } \\
\hline GRUPO & ANÁLISE & $\begin{array}{c}\text { EXTRATOS DA PRODUÇÃO TEXTUAL DOS } \\
\text { ALUNOS EM CADA GRUPO }\end{array}$ \\
\hline Grupo o1 & $\begin{array}{l}\text { O grupo } 1 \text { procurou selecionar alguns } \\
\text { elementos contidos nas cenas que } \\
\text { remetessem à química. Esse grupo focou } \\
\text { em comentar apenas sobre os trechos do } \\
\text { filme, mas não fez nenhuma relação clara } \\
\text { com os conceitos químicos. }\end{array}$ & $\begin{array}{l}\text { "Em uma das cenas foi visto sobre cianetos e } \\
\text { também sobre as reações químicas das quais foram } \\
\text { produzidas várias substâncias com produtos } \\
\text { diferentes". }\end{array}$ \\
\hline Grupo 02 & $\begin{array}{l}\text { Este grupo não conseguiu fazer uma } \\
\text { ralação esperada com a química. Foi citado } \\
\text { apenas alguns fatos em que os alunos } \\
\text { fizeram a suposição que poderia haver algo } \\
\text { científico. }\end{array}$ & $\begin{array}{l}\text { “Também tem outra cena que Sherlock Holmes está } \\
\text { no rio, explode bombas, que quando explodem tem } \\
\text { uma coloração rosa, eu acho que também tem } \\
\text { algum produto químico nas explosões”. }\end{array}$ \\
\hline Grupo 03 & $\begin{array}{l}\text { O grupo } 3 \text { descreveu nos textos as cenas } \\
\text { que falavam sobre líquidos inflamáveis e } \\
\text { sobre as armas químicas. A relação com a } \\
\text { química não foi feita com tanta clareza, } \\
\text { apenas foram levantadas hipóteses sobre o } \\
\text { que poderia ter ocorrido nas cenas. }\end{array}$ & $\begin{array}{l}\text { "Uma máquina que tinha uma substância que } \\
\text { produzia um gás que mataria todos ali". }\end{array}$ \\
\hline Grupo 04 & $\begin{array}{l}\text { O grupo } 4 \text { fez alguns comentários sobre os } \\
\text { elementos químicos que surgiram no } \\
\text { decorrer do filme. Foi notado que eles não } \\
\text { conseguiram relacionar diretamente com } \\
\text { os conceitos químicos. }\end{array}$ & $\begin{array}{l}\text { "Falou no filme que uma substância de cobre entra } \\
\text { em contato com a água". }\end{array}$ \\
\hline
\end{tabular}

De uma forma geral, a partir do Quadro o2, pode-se observar que os alunos conseguiam ver "algo" com Química no filme, como por exemplo a presenta do cianeto (grupo 1), a explosão e mudança de coloração (grupo 2), a máquina que produzia gás (grupo 3) e o cobre em contato com a água (grupo 4). Porém, eles não foram capazes de explicar, quimicamente, o que estava por trás de cada um desses processos. Mesmo assim, nota-se que as cenas levantadas pelos grupos convergem com alguns objetos ficcionais que foram identificados com elementos linguísticos, que remetiam às reações químicas, elementos e substâncias, conteúdos básicos da Química.

A não percepção de outros conceitos químicos nas cenas do filme pode representar uma não construção de conhecimentos prévios suficientes para perceberem alguma relação da Química com o filme. Possivelmente isso fez com que apenas conceitos básicos, como reações químicas e o nome de elementos e substâncias tenham chamado a atenção dos grupos. Ressalta-se que, como o filme foi inserido em uma oficina sobre Química, os alunos sabiam que discussões envolvendo conteúdos químicos poderiam acontecer. Dessa forma, existia uma pré-disposição em prestar atenção na emergência de conceitos químicos durante as cenas. Um argumento que se pode levantar na tentativa de explicar essa falta de percepção em outros conceitos está na análise com o plano conceitualfenomenológico. Como todos os conteúdos que foram listados se apresentavam em elementos linguísticos, estes passaram desapercebido, sendo a atenção dos alunos voltada mais para elementos fenomenológicos, como máquinas, explosões, bombas e outros fenômenos visuais.

No terceiro encontro da oficina, no qual se deu a apresentação de um seminário, os alunos apresentaram explicações das seis cenas com base em conceitos químicos discutidos na aula expositiva 
dialogada do segundo encontro. As seis cenas indicadas para os alunos explicarem continham elementos linguísticos do plano conceitual-fenomenológico envolvendo os conteúdos químicos descritos anteriormente.

No Quadro 4, apresentam-se extratos de algumas falas dos grupos durante o seminário, representando como eles explicavam as cenas com base nos conceitos químicos estudados.

Quadro 4: Seminários pós exibição do filme.

\begin{tabular}{|l|l|l|}
\hline \multicolumn{3}{|c|}{ ATIVIDADE 2 - SEMINÁRIOS } \\
\hline GRUPO & ANÁLISE & EXTRATOS DE FALAS NO SEMINÁRIO \\
\hline Grupo o1 & $\begin{array}{l}\text { Este grupo explicou a cena extrapolando os } \\
\text { conceitos químicos envolvidos, } \\
\text { relacionando, também, com a alquimia. }\end{array}$ & $\begin{array}{l}\text { "Em uma cena do filme um dos personagens fala } \\
\text { que estão tentando misturar ciência com magia. } \\
\text { Isso é pelos desenhos feitos na janela que tinha } \\
\text { alguns símbolos que lembra os desenhos dos } \\
\text { alquimistas". }\end{array}$ \\
\hline $\begin{array}{l}\text { Grupo } \\
\text { o2 }\end{array}$ & $\begin{array}{l}\text { Explicou algumas reações químicas a partir } \\
\text { da fala dos personagens contidas nas cenas }\end{array}$ & $\begin{array}{l}\text { "Eles usaram uma combinação de potássio e } \\
\text { magnésio com ácido sulfúrico para as mais variadas } \\
\text { finalidades". }\end{array}$ \\
\hline $\begin{array}{l}\text { Grupo } \\
\text { 03 }\end{array}$ & $\begin{array}{l}\text { Semelhante ao grupo o1, extrapolou as } \\
\text { explicações sobre os conceitos e associou } \\
\text { com elementos da história, } \\
\text { contextualizando o conteúdo. }\end{array}$ & $\begin{array}{l}\text { O cianeto pode ser usado como arma química e foi } \\
\text { usado com esse objetivo pela união soviética na } \\
\text { guerra fria". }\end{array}$ \\
\hline $\begin{array}{l}\text { Grupo } \\
\text { 04 }\end{array}$ & $\begin{array}{l}\text { Explicou como a ação de alguns elementos } \\
\text { e substâncias pode ser benéfica ou maléfica } \\
\text { para o ser humano, usando como exemplo } \\
\text { uma das cenas selecionadas. }\end{array}$ & $\begin{array}{l}\text { "Ele morreu porque teve contato com uma grande } \\
\text { quantidade de cobre que estava presente na água da } \\
\text { banheira e por conta disso ele acabou tendo uma } \\
\text { parada respiratória". }\end{array}$ \\
\hline
\end{tabular}

Nos seminários foi possível observar certa dificuldade nos alunos em expressar suas ideias. Porém, em alguns momentos, como mostra a o Quadro 4, eles conseguiram explicar algumas das cenas selecionadas a partir dos conceitos e definições associados aos objetos ficcionais. Durante o seminário, intervenções foram feitas de forma que ficassem claros para os alunos os conteúdos químicos presentes nas cenas. É possível observar que, possivelmente, com base na exposição do conteúdo realizada no encontro anterior, dois grupos (1 e 3) foram capazes de extrapolar as cenas do filme, fazendo relações do conteúdo químico com outras situações, como o contexto da Alquimia e o contexto histórico sobre o uso do cianeto na Guerra Fria.

A etapa final da oficina foi a produção textual, em que os grupos deveriam escrever, em forma de recapitulação, os conteúdos químicos estudados durante os encontros, remetendo, mais uma vez, às cenas do filme Sherlock Holmes. No Quadro 5 apresentam-se alguns extratos de textos que ilustram como os alunos fizeram relações das cenas com os conteúdos químicos.

Quadro 5: Análise da produção textual pós seminário.

\begin{tabular}{|l|l|l|}
\hline \multicolumn{3}{|c|}{ ATIVIDADE o3- PRODUÇÃO TEXTUAL FINAL - ANÁLISE CONCEITUAL } \\
\hline GRUPO & \multicolumn{1}{|c|}{ ANÁLISE } & \multicolumn{1}{|c|}{$\begin{array}{c}\text { EXTRATOS DA PRODUÇÃO TEXTUAL DOS } \\
\text { ALUNOS EM CADA GRUPO }\end{array}$} \\
\hline Grupo 01 & $\begin{array}{l}\text { O último texto deste grupo mostrou como } \\
\text { a química estava presente no filme, } \\
\text { ilustrando com algumas cenas. }\end{array}$ & $\begin{array}{l}\text { "Os odores que ele identificou no ar foram: Sulfato } \\
\text { de amônia, putrefação, formaldeído, e perfume } \\
\text { Francês. Essas percepções foram obtidas pela } \\
\text { identificação das propriedades organolépticas". }\end{array}$ \\
\hline Grupo 02 & $\begin{array}{l}\text { Este grupo também explicou algumas } \\
\text { cenas a partir da noção de misturas de } \\
\text { substâncias para que ocorra uma reação } \\
\text { química. }\end{array}$ & $\begin{array}{l}\text { "Eles usaram uma combinação de potássio e } \\
\text { magnésio com ácido sulfúrico para tentar } \\
\text { desvendar o que o vilão tentava esconder". }\end{array}$ \\
\hline
\end{tabular}




\begin{tabular}{|c|c|c|}
\hline Grupo 03 & $\begin{array}{l}\text { O grupo } 3 \text { tentou reproduzir o que foi } \\
\text { falado no seminário, acerca do contexto } \\
\text { histórico em torno do uso do cianeto na } \\
\text { guerra, fazendo uma relação com uma das } \\
\text { cenas do filme. }\end{array}$ & $\begin{array}{l}\text { "O cianeto provocou a cor azulada no rabo do rato } \\
\text { e tem um aroma de amêndoas. Foi usado como } \\
\text { arma química pelos Estados unidos e pela União } \\
\text { soviética, já que o cianeto é um gás extremamente } \\
\text { tóxico e mata rapidamente”. }\end{array}$ \\
\hline Grupo 04 & $\begin{array}{l}\text { Este grupo foi além do que se apresentou } \\
\text { no seminário, mostrando outros } \\
\text { elementos, possivelmente, provenientes } \\
\text { da pesquisa realizada entre a exibição do } \\
\text { filme e a apresentação dos seminários. } \\
\text { Assim, os alunos explicaram a cena da } \\
\text { morte do personagem a partir da } \\
\text { compreensão dos efeitos do íon cobre no } \\
\text { organismo humano. }\end{array}$ & $\begin{array}{l}\text { “O cobre é um metal que em pouca quantidade faz } \\
\text { bem ao corpo humano porque ajuda na absorção } \\
\text { mais rápida de vitamina C, mais que em grande } \\
\text { quantidade causa dores, diarreia, febre, parada } \\
\text { respiratória e até a morte”. }\end{array}$ \\
\hline
\end{tabular}

Na produção textual, nota-se que os grupos o1 e 04 exploraram bem os conceitos químicos relacionados às cenas selecionadas, atingindo o objetivo da oficina. Esse objetivo foi parcialmente atingindo quando se analisa os grupos 02 e 03 , visto que ainda apresentaram as dificuldades identificadas desde a primeira produção textual, no início da oficina. Além disso, o grupo o3, basicamente, reproduziu a fala do seminário. Destaca-se que a análise com o plano conceitualfenomenológico foi útil, de forma que nos mostrou em quais cenas/objetos ficcionais os alunos poderiam perceber a Química, de forma a conduzir todas as demais atividades da oficina.

\section{CONSIDERAÇÕES FINAIS}

Este artigo teve como objetivo apresentar uma análise dos objetos ficcionais presentes no filme Sherlock Holmes que serviu para elaboração e execução de uma oficina com o uso desse filme para alunos do ensino médio e, além disso, observar como esses alunos percebiam a Química nas cenas selecionadas com base na análise realizada. Com o uso do plano conceitual-fenomenológico de Piassi e Pietrocola (2006), os objetos ficcionais foram analisados, havendo a identificação de 13 elementos linguísticos. Esta análise resultou no recorte de seis cenas para trabalho para os seminários além da seleção dos seguintes conteúdos: propriedades organolépticas, transformações químicas e físicas, elementos e substâncias.

Durante a execução da oficina, após a exibição do filme, notou-se que os alunos, inicialmente, apresentaram dificuldades em levantar conteúdos de Química que poderiam estar presentes nas cenas. Tal dificuldade pode ser devido à falta de domínio dos conceitos que estavam presentes no filme. Uma segunda hipótese, é que eles prestaram mais atenção nos elementos fenomenológicos do que nos linguísticos, no qual os conteúdos selecionados estavam presentes. Essa dificuldade foi amenizada ao longo da oficina, devido à exposição teórica dos conteúdos e às atividades que culminaram no seminário e na última produção textual. Assim, nota-se que, ao decorrer da oficina, alguns grupos, como mostrado nos quadros, extrapolaram o contexto do filme e deram exemplos de outras situações, como na história da Ciência, de como aqueles conteúdos químicos estavam presentes.

Por fim, foi possível observar que a análise inicial dos objetos ficcionais do filme Sherlock Holmes permitiu um delineamento mais refinado das cenas a serem utilizadas em sala de aula para a oficina. Contudo, notou-se que os alunos, inicialmente, não foram capazes de perceber os mesmos elementos linguísticos que foram identificados na análise, não por causa de uma limitação da categorização, mas devido à falta de domínio de alguns conceitos por parte dos alunos. Tal dificuldade foi amenizada ao longo da oficina, fazendo com que os alunos se apropriassem dos conteúdos e relacionassem as cenas com os elementos linguísticos dos objetos ficcionais presentes nas cenas selecionadas. 


\section{REFERÊNCIAS}

ALLEN, L.D. No mundo da ficção científica. São Paulo: Summus, 1976.

CARVALHAL, F. C. A. Instituto Nacional De Cinema Educativo: Da História Escrita À História Contada - Um Novo Olhar. 2009. Disponível em: <HTTP://www.mnemocine.art.br.> Acesso em: 29 de maio de 2017.

CRESPO, L. C.; GIACOMINI, R. As Atividades Lúdicas No Ensino De Química: uma revisão da Revista Química Nova Na Escola e das Reuniões Anuais da Sociedade Brasileira de Química. In: Anais do VIII Encontro de Pesquisa em Educação em Ciências (ENPEC). Campinas-SP. 2011.

FERRÉS, J. Vídeo e Educação. 2. Ed. Porto Alegre: Artes Médicas. 1996.

FRANCO, M. S. Escola audiovisual. 1987. Tese (Doutorado em Comunicação e Artes): USP, São Paulo, 1987.

MELO, S. K. S. O Vídeo Como Recurso Pedagógico: Análise De Sequências Didáticas De Licenciandos Em Química. Monografia (Licenciatura em Química): UFRPE, Recife, 2013.

MORÁN, J. M. O Vídeo na Sala de Aula. Comunicação e Educação. v. 2; p. 27-35, 1995.

GOMES-MALUF, M.C. O filme Jurassic Park e a tecnologia do DNA recombinante: O uso da ficção cientifica no ensino de ciências, 2001 Dissertação (Mestrado em Educação para a Ciência) - Faculdade de Ciências, Universidade estadual Paulista, Bauru, 2001.

GOMES-MALUF, M.C; SOUZA, A.R. A ficção científica e o ensino de ciências: o imaginário como formador do real e do racional. Ciência e educação. v. 14, n.2, p.271-282, 2008.

PIASSI, L. P. C.; PIETROCOLA, M. Possibilidades dos filmes de ficção científica como recurso didático em aulas de Física: a construção de um instrumento de análise. X Encontro de Pesquisa em Ensino de Física. Sociedade Brasileira de Física. São Paulo, 2006.

PIASSI, L. P. C.; PIETROCOLA, M. Ficção científica e ensino de ciências: para além do método de encontrar erros em filmes. Educação e pesquisa, v. 35, n. 3, p 525-540, 2009.

QUINTINO, C. P.; RIBEIRO, K. D. F. A Utilização de filmes no processo de ensino aprendizagem de Química no Ensino Médio. In: Anais do XV Encontro Nacional de Ensino de Química (XV ENEQ) - Brasília, DF, Brasil, 2010.

SANTOS, P. N.; AQUINO, K. A. S. Utilização do Cinema na Sala de Aula: Aplicação da Química dos Perfumes no Ensino de Funções Orgânicas Oxigenadas e Bioquímica. Química Nova na Escola, v. 33, n. 3, 2011.

SOARES, M. H. F. B. Jogos e atividades lúdicas no ensino de química: uma discussão teórica necessária para novos avanços. Revista Debates em Ensino de Química (REDEQUIM). v. 2, n. 2, 2016.

Gustavo Silva de Amorim: É aluno do curso de Licenciatura em Química da Unidade Acadêmica de Serra Talhada, Universidade Federal Rural de Pernambuco.

E-mail: gusamorim535@gmail.com

João Roberto Ratis Tenório da Silva: Professor da Universidade Federal de Pernambuco, lotado no Núcleo de Formação Docente - Centro Acadêmico do Agreste. É licenciado em Química e mestre em Ensino de Ciências pela UFRPE (Universidade Federal Rural de Pernambuco) e, atualmente, doutorando em Psicologia Cognitiva pela UFPE (Universidade Federal de Pernambuco).

E-mail: joaoratistenorio@gmail.com 